\title{
RESEARCH ON DYNAMIC CHANGE OF GRASSLAND IN WEST JILIN PROVINCE BASED ON 3S TECHNOLOGY
}

\author{
Zhiming Liu, Nanyan Ling \\ Northeast Normal University, Changchun, China, 130024
}

Abstract: Grassland had been interpreted with the method that combined supervised and non-supervised classifications using Landsat data in autumns 1986, 1996 and 2000. The amelioration of algorithm promoted the accuracy. With the support of RS and GIS, spatial information of grassland landscape in west Jilin province from 1986 to 2000 was extracted, spatio-temporal dynamics of grassland and change of grassland landscape patterns were analyzed. The results show: 1) The grassland environment in the west Jilin is exacerbating and the area of grassland is decreasing by an average of $4.5 \times 10^{4}$ hectares a year, moreover, the grassland degeneration is severe and the area of degeneration is $81.1 \%$ of the total. 2) The degeneration of the grassland is heavier and the proportions of moderate and heavy degenerated grassland are heightening obviously, so their evaluative trends are remarkable. 3) The degenerated grassland is mainly converted into cropland and saline-alkalized land, converted area reaches $992351.4 \mathrm{hm}^{2}$ and $563031.1 \mathrm{hm}^{2}$. 4) The total dynamic degree of grassland is a minus value. During 1986-1996, high coverage grassland has a strong effect on change of whole grassland. The fastest degraded area is low coverage grassland from 1996 to 2000.

Keywords: grassland, spatio-temporal change, dynamic degree, remote sensing images, geography information system, west Jilin province

\section{INTRODUCTION}

Remote Sensing is provided with excellent characteristics such as the exact, macroscopical, dynamic, frequent large area observation. On the other hand, Geographic Information Systems has the advantage on data processing

Liu, Z. and Ling, N., 2008, in IFIP International Federation for Information Processing, Volume 258; Computer and Computing Technologies in Agriculture, Vol. 1; Daoliang Li; (Boston: Springer), pp. 277-285. 
and dynamic analysis. The practices indicate that study on the spatiotemporal changes of grassland resources with the support of RS and GIS is very effective. The paper analyzes and reveals the spatio-temporal regulations and momentum of grassland development in west Jilin province since 1986.

\section{GENERAL SITUATION OF THE INVESTIGATED REGION}

The west Jilin province $\left(121^{\circ} 38^{\prime}-126^{\circ} 11^{\prime} \mathrm{E}, 43^{\circ} 59^{\prime}-46^{\circ} 18^{\prime} \mathrm{N}\right)$, which is located in the east Kerqin Steppe, one of the biggest prairies in the world, and the south-central Songnen Plain. The dimensionality acreage of region amounts to $47671 \mathrm{~km}^{2}$ that occupies $25.5 \%$ in total domanial acreage in Jilin province. It is located in Semiarid Agro-pastoral and belongs to temperate zone continental monsoon climate whose characteristics are long cold winter, short-lived sweltering summer, plenty wind and little rain. The annual average temperature is $3-6^{\circ} \mathrm{C}$ and the annual precipitation is 400 $500 \mathrm{~mm}$, otherwise, the annual evaporation is $1842 \mathrm{~mm}$ in this region.

Firstly, on division, it is a transitional area between the region where agriculture is dominant and the region where mixed pastoral farming area is leading. Secondly, on natural zonation, it lies between the transitional area of temperate zone semi-humid meadow grassland zone and temperate zone semi-dry grassland which also called ecological and climatic fragile zone chestnut soils. Thirdly, on landform, it is the transitional area from Songnen Plain to the downstream plain of Liao river. Finally, on climate, it is located in the transitional area between humid East Asian monsoon region and arid continental area. The investigated region is so sensitive to the environmental changes which happen as a result of the transformation of climate and human activities that it has been concerned by domestic and overseas scholars as an area that responds to global change exceedingly and is the ecological and climatic fragile zone (Chen Da-Ke, 1995; Wang Dongyan et a1., 2002; Qiu Shanwen et a1., 2003).

\section{THE METHOD OF STUDY}

\subsection{Data processing}

The data processing which included normal false color composing and accurate correction as well as registration and enhancement of images was accomplished by using Landsat data in 1986, 1996 and 2000 and 1: 100000 
land-use map. The control points were selected to carry through quadratic polynomial fitting correction based on the recently land-use map. The treated TM images matched with the digital border line well, and the error was two pixels at most.

According to the actual situation of the investigated area, the grassland was divided into three categories: high coverage density area, moderate coverage density area and low coverage density area in accordance with the national land use classification system. High coverage density grassland denotes the natural grassland, improved grassland and mowing grassland whose coverage densities are more than $50 \%$. Besides that, the moisture conditions of this kind of lawn are generally good, and the grass spreads sparsely. Moderate coverage density grassland denotes the natural grassland and improved grassland whose coverage densities are between $20 \%$ and $50 \%$. It is deficient in water, where the grass is also relative sparse. Low coverage density grassland is the natural grassland whose coverage density is between $5 \%$ and $20 \%$. Such lawn is lack of water badly, where the grass is quite sparse. Therefore, the conditions applied to animal husbandry are very poor.

\subsection{The model of grassland dynamic change}

The land dynamic degree is quantitative changes of some or other type of land-use within a period of time in a certain study area. Using dynamic model to analyze the spatial-temporal changes of regional grassland can truly reflect the exquisite degree of its changes. The expression is:

$$
L C=\left(U_{b}-U_{a}\right) \cdot U_{a}^{-1} \cdot T^{-1} \cdot 100 \%
$$

where: $L C$ represents dynamic degree of a certain type of land-use within study time; $U_{a}$ and $U_{b}$ represent the number of the certain land-use type at the beginning and at the end of the research; $T$ represents the time that the study covered.

\section{INTERPRETATION OF GRASSLAND RESOURCES BY REMOTE SENSING TECHNIQUES}

\subsection{Identification of grassland}

We identified and extracted the grassland information on the TM images achieved by using the method of computer classification discrimination based on pixel. This method was to apply remote sensing spectral 
information, space information and time information to identify and classify the target. The non-supervised and supervised classifications were the general methods of classification (Guo Defang, 1987). We combined both methods and improved the algorithm in order to improve the accuracy of remote sensing satellite images automatic recognition (Li Xia; Jiao Weili, 1994).

\subsubsection{Application of classification method}

It was difficult to select training area when the classifying process because of regional various distribution types and sporadic size of the upper features. Thus, first we get the initial spectral information type map in the area by using dynamic clustering method contained by non-supervised classification, and then compared it with the recently land-use map to determine the relationship between the actual type of objects and spectral information. Artificial visual interpretation process was imported to this step that was the key classification process. The dynamic clustering means that the cluster center can be modified and changed continually, and the cluster number can be also changed and adjusted continuously in the classification process to make the classification more reasonable. As the classification emphasis was more on particular classification for grassland, we merged farmland, woodland and other water bodies correspondingly. Standard deviation means were used to establish the initial category center, and 13 categories spectral information type maps were obtained after iterative convergence. Such classification had better effect on large categories of features, but it was difficult to accurately differentiate some categories which had similar spectra value such as different levels of degradation of grassland.

The results of non-supervised classification were contradistinguished with the actual object categories, and then the grassland was further classified through surveying the samples, selecting the training area, and using supervised classification with expression (1) to deal with the results. Supervised classification adopted maximum likelihood classification method, which was based on Byes principle that pursues the minimum loss of average classification of the entire data sets, so that each data can be classified into the most similar category. The above method was called algorithms I. 
Discriminant function:

If $G_{i}(\mathrm{x}) \geq G_{j}(\mathrm{x}) \mathrm{i} \neq \mathrm{j}(\mathrm{i}, \mathrm{j}=1,2, \ldots, \mathrm{N})$

then $\mathrm{x} / \mathrm{w}_{\mathrm{i}}$

In the expression, $\mathrm{i}$ and $\mathrm{j}$ represent sequence numbers of categories; $\mathrm{w}_{\mathrm{i}}$ represents sign of categories; $\mathrm{P}\left(\mathrm{w}_{\mathrm{i}}\right)$ represents prior probability of $\mathrm{w}_{\mathrm{i}} ; \mathrm{x}$ represents gray value of identified pixel; $G_{i}(x)=P\left(x / w_{i}\right) P\left(w_{i}\right)$ represents set of function for identifying; $\mathrm{P}\left(\mathrm{x} / \mathrm{w}_{\mathrm{i}}\right)$ represents conditional probability of $\mathrm{x}$ for $\mathrm{w}_{\mathrm{i}} ; \mathrm{N}$ is the total number of categories.

The $\mathrm{x}$ was introduced into the various types of discriminant function when a certain pixel needed to be identified. Then the classification results were checked to determine whether the training area needs to be corrected or reclassified or not according to different types of image color and the results of unsupervised classification, we selected 10 training areas whose according categories of the surface features.

\subsubsection{Improve classification accuracy}

The entire classification process above all was completed with support of Geographic Information Systems (GIS). Regarding some complicated categories which were difficult to distinguish we used the algorithm II:

$$
\begin{aligned}
& F_{\mathrm{i}}=\sum_{\mathrm{j}=1}^{\mathrm{N}}\left|\mathrm{R}_{\mathrm{i}}-\mathrm{R}_{\mathrm{j}}{ }^{\prime}\right| \\
& R_{j}=\mathrm{n}_{\mathrm{j}} / \mathrm{n}_{\mathrm{i}} \quad(\mathrm{i}, \mathrm{j}=12, \ldots, \mathrm{N})
\end{aligned}
$$

where: $\mathrm{i}$ and $\mathrm{j}$ represent sequence numbers of categories; $\mathrm{R}_{\mathrm{j}}$ represents normalization probability of the training sample data for the $j$ type; $R_{j}^{\prime}$ represents normalization probability of the local area for the $\mathrm{j}$ type; $n_{i}$ represents the number of pixels which i type of training samples belonged to the $\mathrm{j}$ category; $\mathrm{N}$ represents the total number of categories.

Algorithm II is different from algorithm I because that it is not the classification of a single pixel as object but the classification of comprehensive analysis and judgment which based on a particular pixel and the surrounding linked pixels. On the basis of supervised classification with algorithm I, we can dispose the data with algorithm II, to further improve the classification accuracy by utilizing spatial information. 


\section{RESULTS AND ANALYSIS}

The desertification, salinization and alkalization of grassland in the region were intensified along with the rapid growth of population, the weak consciousness of protection of grassland. Therefore grassland vegetation decreased or disappeared, the grassland biomass reduced sharply and grassland degenerated at last. Based on the results of remote sensing interpretation that were achieved by interpreting the TM images in 1986, 1996 and 2000, the degrees of regional grassland degradation were classified into mild, moderate and heavy three levels (Northern Grassland Resources Survey Office, 1986). Then in support of GIS, the grading statistics and subarea statistics were accomplished. At last, the situation and development trend of grassland degradation in west Jilin Province were analyzed.

\subsection{Obviously decreased area of grassland}

\subsubsection{The analysis of time-series change on grassland area}

According to the spatial information of remote sensing images in the studied region in the different periods, we analyzed the statistics of high, moderate and low coverage density grassland area Table 1 and area change of different types of grassland in 15 years. From Table 1, we can find out that the area of grassland had reduced $42.1 \%$ since 15 years ago, and the average annual reduction was $2.81 \%$. The decreasing trend was obvious, which showed that grassland degradation was from bad to worse. High coverage density area continued to decrease with large quantity change of the area, and the rate of net reduction reached 53\%, which indicated that the degradation of this grassland category was most serious. Moderate and low coverage density areas didn't change a lot from 1986 to 1996, but from 1996 to 2000 both areas represented a reducing trend overall respectively.

Table 1. Changes of grassland area $\left(\mathrm{hm}^{2}\right)$ and dynamic degree in west Jilin province

\begin{tabular}{lcclcc}
\hline Type of grassland & $\begin{array}{l}\text { Area of } \\
\text { grassland } \\
\text { in 1986 }\end{array}$ & $\begin{array}{l}\text { Area of } \\
\text { grassland } \\
\text { in 1996 }\end{array}$ & $\begin{array}{l}\text { Area of } \\
\text { grassland } \\
\text { in 2000 }\end{array}$ & $\begin{array}{l}\text { Dynamic } \\
\text { degree } \\
1986-1996\end{array}$ & $\begin{array}{l}\text { Dynamic } \\
\text { degree } \\
1996-2000\end{array}$ \\
\hline $\begin{array}{l}\text { The high coverage } \\
\text { density grassland }\end{array}$ & 1052433.0 & 557218.7 & 494455.5 & $-4.7 \%$ & $-2.8 \%$ \\
$\begin{array}{l}\text { The moderate } \\
\text { coverage density } \\
\text { grassland }\end{array}$ & 631459.8 & 623523.9 & 466486.3 & $-0.1 \%$ & $-6.3 \%$ \\
$\begin{array}{l}\text { The low coverage } \\
\text { density grassland }\end{array}$ & 41407.2 & 94357.4 & 37958.2 & $12.8 \%$ & $-14.9 \%$ \\
\begin{tabular}{l} 
Summation \\
\hline
\end{tabular} & 1725300.0 & 1275100.0 & 998900.0 & $-2.6 \%$ & $-5.4 \%$ \\
\hline
\end{tabular}




\subsubsection{The analysis of grassland dynamic degree}

The grassland dynamic degree can be used to quantify the instance of grassland degradation, so the grassland dynamic degrees in the studied region from 1986 to 2000 were calculated according to expression (1). Table 2 showed that from 1986 to 1996, grassland dynamic degrees changed drastically. Among them, the dynamic degrees of high coverage density grassland were negative, and the values of moderate coverage grassland density were very small though they were also negative. Otherwise, low coverage density grassland dynamic degrees were positive value and the total dynamic degree accorded with the one of high coverage density grassland which were both $-2.6 \%$. It indicated that in this period changes of high coverage density grassland have greater influenced on the unitary grassland change whereas the change of the total grassland area was smaller. According to the analysis of absolute values of dynamic degree, the low coverage grassland density grew the fastest because of its biggest value. The values of moderate and high coverage density grassland were relatively small and they developed comparatively slowly. From 1996 to 2000, various types of grassland and the total dynamic degree were all negative, which suggested that all types of grassland were degenerating, and the absolute values of low coverage density grassland dynamic degree were most. Thus the degradation of low coverage density grassland was the fastest.

\subsubsection{The grassland area transfer analysis}

In order to more accurately realize the degraded states of different types grassland, the values of high, moderate and low coverage grassland area transfer were acquired by using the land-use map and distribution map in 1986, 1996 and 2000 in support of spatial analysis function of ArcGIS software. The study showed that from 1986 to 1996, the total number of grassland changed to other land-use types reached $1136843.3 \mathrm{hm}^{2}$. The grassland most converted to cropland, saline-alkali land and woodland, and especially the converted area of the high coverage density one reached $619765.9 \mathrm{hm}^{2}$ which was the largest. It showed that the grassland in this period was so exploited in excess by human that caused large areas of grassland to be changed to farmland and woodland, at the same time, grassland degradation and salinization were more serious. Undoubtedly, all above all leaded to the further deterioration of ecological environment in the studied area and seriously affected the development of stockbreeding in Western Jilin, so we should pay more our attention to them. From 1995 to 2000, the grassland degradation represented an increasing trend, and $769268.7 \mathrm{hm}^{2}$ grassland translated into other land-use types. More grassland degenerated into saline-alkali land compared with the previous period, and 
the trend aggravated. Especially, the high coverage density grassland degenerated most seriously. Despite the areas of grassland which changed to farmland and woodland were reduced, they still can not be ignored for their considerable proportions occupied.

\subsection{The exacerbated degree of grassland degradation}

The regional grassland degenerated seriously which also represented at the change of degradation degree. According to the grassland resources survey results which were achieved by using of the data of TM in 1986 and 2000 , the areas of grassland degradation and the distribution of degradation grade Table 2 that belonged to the western counties (cities) were calculated. Since 1986, the area of grassland degradation had increased $47.8 \times 10^{4} \mathrm{hm}^{2}$ and the proportion had reached $86 \%$. The light degenerated grassland decreased $66.4 \%$, moderately degraded grassland increased $137.8 \%$, and the heavy degenerated grassland increased most, up to $360.9 \%$. All data above showed that the degree of grassland degradation had increased. In view of proportion, we can see that the grassland area in this region accounted $36.2 \%$ for the total area of regional land in 1986 and the degenerated grassland area accounted $32.2 \%$ for the area of grassland, however, the regional grassland area accounted $26.7 \%$ for the total regional land area while the area of degenerated grassland occupied to $81.1 \%$ of the grassland area in 2000 .

Table 2. The degeneration of grassland in the West Jilin $\left(10^{4} \mathrm{hm}^{2}, \%\right)$

\begin{tabular}{lrcrc}
\hline Type of grassland & \multicolumn{2}{c}{ In 1986 } & \multicolumn{2}{c}{ In 2000 } \\
\cline { 2 - 5 } & area & proportion & \multicolumn{1}{c}{ area } & proportion \\
\hline Non-degenerated grassland & 116.93 & 67.8 & 24.16 & 18.9 \\
Degenerated grassland & 55.60 & 32.2 & 103.35 & 81.1 \\
Light degenerated grassland & 25.78 & 46.4 & 8.65 & 8.4 \\
Moderate degenerated grassland & 19.16 & 34.5 & 45.57 & 44.1 \\
Heavy degenerated grassland & 10.66 & 19.2 & 49.13 & 47.5 \\
\hline
\end{tabular}

\section{REFERENCES}

Chen Da-Ke. Introduction to Economic Ecology $[\mathrm{M}]$. Harbin: the Northeast Forestry University Press, 1995:63-68.

Guo D F. Computer image processing of remote sensing and pattern recognition. Beijing: Press of electronic industry, 1987:243-390.

Li X, Jiao W L. A study on improving the classification accuracy on TM remote sensing image. Remote Sensing Technology and Application, 1994, 9(3):30-35.

Northern Grassland Resources Survey Office. Technical Rules of Grassland Resources Survey [M]. Beijing: China Agricultural Press. 1986. 
Qiu S W, Zhang B, Wang Z C. Status, features and management practices of land desertification in the west of Jilin [J]. Geography Science, 2003, 23(2):188-192.

Wang D Y, Xu W L, Feng H, et al. Study on the element abundances and their characteristics of soil in grassland from western Jilin province. Scientia Geographica Sinica, 2002, 22(6):763-768. 